\title{
Erratum to: Complex management of resistant oral herpes simplex virus infection following hematopoietic stem cell transplantation: potential role of topical cidofovir
}

Joel B. Epstein ${ }^{1,2}$ - Seda Gharapetian ${ }^{2}$ - Ali R. Rejali ${ }^{2}$ - Rachel Zabner ${ }^{2}$. Michael Lill ${ }^{1,2,3} \cdot$ Dimitrios Tzachanis $^{3}$

Published online: 8 June 2016

(C) Springer-Verlag Berlin Heidelberg 2016

Erratum to: Support Care Cancer

DOI 10.1007/s00520-016-3264-5

The original version of this paper unfortunately contained error. The name of Seda Gharapetian was incorrectly captured and is corrected in this article.

The online version of the original article can be found at http://dx.doi.org/ 10.1007/s00520-016-3264-5.

Joel B. Epstein

joel.epstein@cshs.org

1 Samuel Oschin Comprehensive Cancer Institute, Cedars-Sinai Medical Center, Los Angeles, CA, USA

2 Cedars-Sinai Health System, Los Angeles, CA, USA

3 Blood and Marrow Transplant Program, University of California, San Diego, San Diego, CA, USA 